\title{
Familial Medullary Thyroid Carcinoma Associated with Cutaneous Lichen Amyloidosis
}

\author{
Amy E. Rothberg, ${ }^{1}$ Victoria M. Raymond, ${ }^{2}$ Stephen B. Gruber, ${ }^{2}$ and James Sisson ${ }^{3}$
}

Background: This is a report of a patient with a novel genotype-phenotype relationship of a c804 mutation of the RET proto-oncogene manifesting as medullary thyroid carcinoma (MTC) and cutaneous lichen amyloidosis (CLA). Summary: Clinical data were obtained for patient appearance and laboratory results. Analyzed were histopathology of the skin lesion and thyroid gland, genetic mutation, and family pedigree. Skin histology and histochemistry were consistent with CLA. Serum calcitonin levels were moderately elevated. Thyroid histology demonstrated a $4 \mathrm{~mm}$ focus of MTC. Measurements of serum parathormone, calcium, and plasma metanephrines were normal. DNA analysis demonstrated a mutation in codon 804 of the RET proto-oncogene resulting in a Valine to Methionine (V804M) substitution. Genetic testing in two siblings revealed the same mutation.

Conclusions: This is the first description of a patient with CLA not associated with a mutation in codon 634. The patient is one of the few with a V804M mutation in whom the clinical expression did not fully conform to the definition of familial MTC.

\section{Introduction}

C UtANeous lichen amyloidosis (CLA) is an uncommon but recognized component of the multiple endocrine neoplasia 2A syndrome (MEN 2A) $(1,2)$. This clinical syndrome has previously been observed only in patients with mutations in codon 634 (c634) of the RET proto-oncogene $(3,4)$. Familial medullary thyroid carcinoma (FMTC) has been defined as presence of MTC in families who do not develop the other features of MEN 2A $(3,5)$. Mutations in c804 with methionine substituted for valine (V804M) have regularly been reported in association with FMTC (6-14) with the exception of two reports of V804M mutation associated with pheochromocytoma $(15,16)$ and two with hyperparathyroidism $(17,18)$.

However, the nonspecific clinical appearance of CLA may obscure its diagnosis, and because the MTC of FMTC is often indolent, CLA may elude diagnosis for decades, particularly in patients who, with a RET mutation of V804M, usually develop MTC in later life. We report a patient with CLA who otherwise appears to exhibit FMTC, and in whom the RET mutation of V804M was found.

\section{Case Report}

In 2008, a 51-year-old woman had endured an intensely, but episodically pruritic, patch in the interscapular area of her left back for over 10 years. In 2000, a dermatologist made the diagnosis of macular amyloidosis secondary to repeated scratching. A glucocorticoid cream provided minimal relief, but no other medication was palliative. Her itch worsened under periods of stress. In 2007, a second dermatologist biopsied the lesion; the histology was interpreted as consistent with cutaneous amyloidosis. An extensive investigation for systemic amyloidosis followed and included a comprehensive metabolic profile with serum calcium, complete blood cell count analysis, C-reactive protein, serum and urine protein electrophoreses, abdominal CT, echocardiography, esophagogastroduodenoscopy, and colonoscopy with biopsies. No abnormality was uncovered. The clinical and histological appearances suggested CLA, and a genetic evaluation followed (see Results).

In 1991, she developed invasive lobular carcinoma of the breast: ER/PR+, ([-] for 0/14 lymph nodes sampled); remission has persisted after lumpectomy, chemotherapy, and external beam irradiation.

Her blood pressure and heart rate were within normal limits. Her thyroid gland neither was enlarged nor exhibited palpable nodules. She had no lymphadenopathy. In the left interscapular area at the T2-T6 level was a hyperpigmented, macular lesion.

\section{Results}

The location of the patient's CLA is shown in Figure 1. Clinically, it appeared as a brownish macule with discrete

\footnotetext{
${ }^{1}$ Division of Metabolism, Endocrinology, and Diabetes, Department of Internal Medicine; ${ }^{2}$ Division of Molecular Medicine and Genetics, Department of Internal Medicine; ${ }^{3}$ Division of Nuclear Medicine, Department of Radiology; University of Michigan, Ann Arbor, Michigan.
} 
areas of excoriation. The histologic pattern demonstrated characteristic features of the disorder, including mild acanthosis and hyperkeratosis. Within the superficial papillary dermis and immediately beneath the dermal-epidermal junction, there were homogenous eosinophilic deposits and also numerous scattered melanophages (Fig. 2A). Insufficient biopsy material prevented staining for amyloid. Repeat biopsy stained with hematoxylin and eosin confirmed the presence of amyloid (Fig. 2B).

DNA sequence analysis was performed to test for the presence of a mutation in exons 10,11,13,14, 15, and 16 of the RET proto-oncogene and detected a mutation in exon 14: 2410G $>$ A (GTC $>$ ATG) giving a substitution of methionine for valine: V804M. With this information, additional tests were ordered. Levels of free fractionated plasma metanephrines were normal: normetanephrine $0.74 \mathrm{nmol} / \mathrm{L}(<0.90)$ and metanephrine $0.34 \mathrm{nmol} / \mathrm{L}(<0.50)$. Intact serum parathyroid hormone was $33 \mathrm{pg} / \mathrm{mL}$ and normal; corresponding calcium was $9.5 \mathrm{mg} / \mathrm{dL}$.

In early 2008, basal serum calcitonin level was $31 \mathrm{pg} / \mathrm{mL}$ (normal $<13$ ). Five and 7 months later, calcitonin levels were 47 and $48 \mathrm{pg} / \mathrm{mL}$, respectively (normal $<8$ ). Thyroid ultrasonography depicted a normal-sized, mildly heterogeneous thyroid gland containing, in the right lobe, a superior hypoechoic nodule measuring $2 \times 3 \times 4 \mathrm{~mm}$, and, in the left lobe, two small cystic nodules, $4 \times 4 \times 5 \mathrm{~mm}$ and $3 \times 6 \times 7 \mathrm{~mm}$.

A total thyroidectomy with central neck compartment dissection excised a $0.4 \mathrm{~cm}$ focus of medullary carcinoma restricted to the left lobe of her thyroid gland (Fig. 3); lymph nodes showed no metastasis. Her carcinoma was stage I. Postoperative calcitonin level was $<5 \mathrm{pg} / \mathrm{mL}$, and expected basal value $<8 \mathrm{pg} / \mathrm{mL}$.

The pedigree of the family is shown in Figure 4. Genetic testing of the patient's 40-year-old sister and 61-year-old brother disclosed the same mutation, but, on careful examination, neither had skin changes. The brother's calcitonin level was moderately elevated at $40 \mathrm{pg} / \mathrm{mL}$; the sister's calcitonin level was within normal limits; neither has undergone ultrasonography of the neck, and each is undecided about

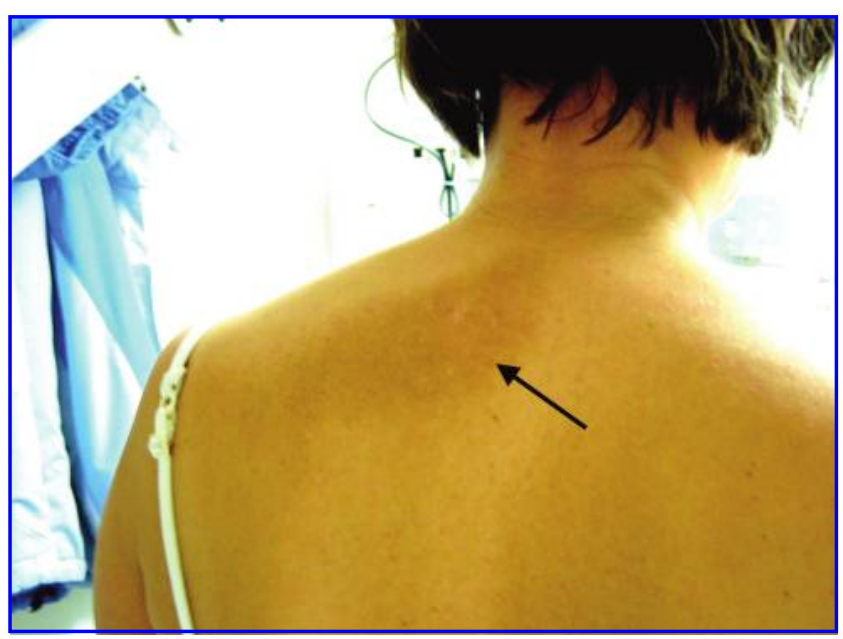

FIG. 1. Cutaneous lichen amyloidosis is seen extending from the midline to the left. Inspection showed excoriations, but otherwise a smooth surface. Color images available online at www.liebertonline.com/thy.

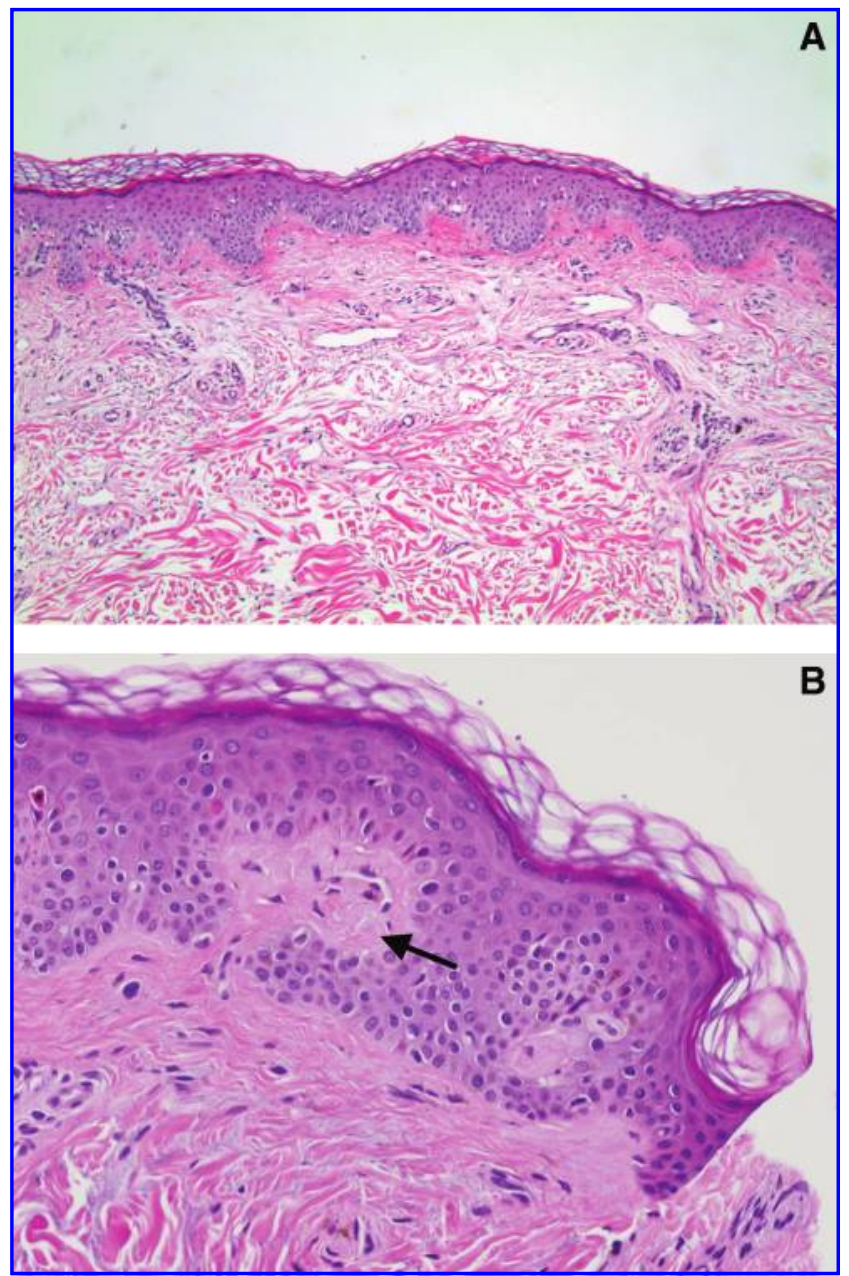

FIG. 2. Photomicrographs of the patient's skin lesion. (A) First skin biopsy $200 \times$ magnification portrays mild acanthosis and hyperkeratosis. Within the superficial papillary dermis, immediately beneath the dermal-epidermal junction, there were homogenous eosinophilic deposits. There were also numerous scattered melanophages. (B) Second biopsy $400 \times$ magnification, stained with hematoxylin and eosin, revealing small globular deposits of amyloid in the papillary dermis (arrow). Color images available online at www .liebertonline.com/thy.

prophylactic thyroidectomy. The patient's mother is living at age 81 years; she has had a single colonic polyp but is otherwise in good health. The mother refused evaluation, but she denies skin abnormalities. The patient's other four siblings do not wish to be tested.

There are four living maternal uncles who are in their 70s and in good health; one maternal uncle died at age 70 years. There are four living maternal aunts in good health. Her maternal grandmother died at age 80 years and had history of diabetes, and her maternal grandfather died young of an unknown cause. Her father died at age 60 years of mesothelioma; he had worked in a foundry. She has three paternal aunts who were diagnosed with breast cancer in their 50s or $60 \mathrm{~s}$. These family members have not been examined, but here is no history of skin disorder or thyroid disease. Consanguinity was absent. 


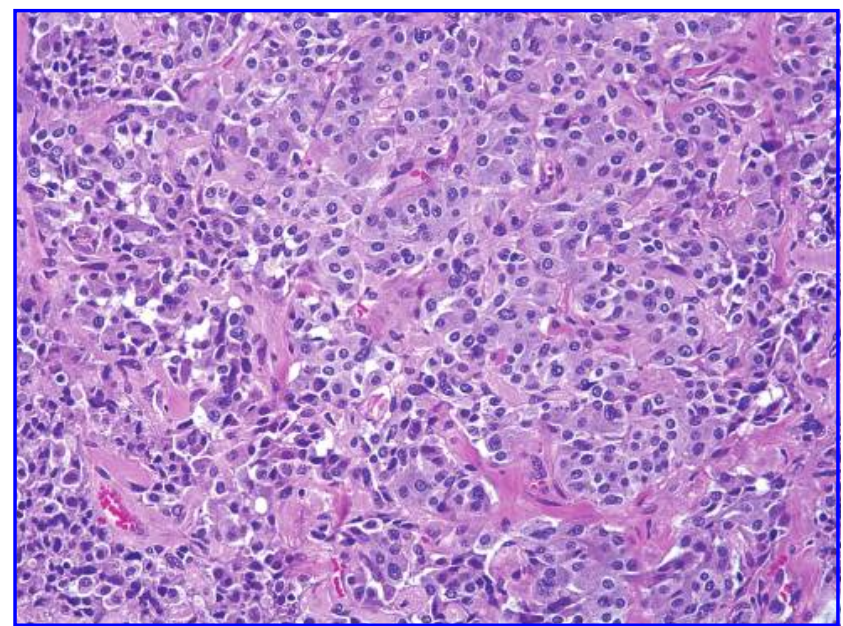

FIG. 3. Photomicrograph of medullary carcinoma consisting of nests of neuroendocrine cells with abundant granular cytoplasm and round to oval nuclei. A few bands of eosinophilic amyloid stroma are present. Original magnification, $200 \times$. Tumor diameter was $4 \mathrm{~mm}$. Color images available online at www.liebertonline.com/thy.

\section{Discussion}

The characteristic features of CLA-pruritic symptoms over years, anatomic location, and histologic changes in the skin (19-22)—were present in our patient. She appears to be the first to manifest CLA with a RET mutation other than c634
$(3,4)$, and the genotype-phenotype relationship of V804M must now include CLA.

Pruritus is usually the first manifestation of CLA; this is in contradistinction to "friction amyloidoses" in which the scratching and hyperpigmentation occur before the pruritus $(19,22,23)$. The rash occurs in the area of repeated scratching and is located in the upper back at either or both interscapular regions. Familial CLA has been described, but in this disorder, the skin disease involves the arms and legs, and patients do not manifest RET mutations (24). In a selected series reported by Robinson (22), 31 of 44 patients had MTC and CLA. The lesions occurred predominantly on the upper back on the right side extending to the midline or bilateral extending across the midline $(19,20,22)$. Age of onset occurred usually before 20 years, with the median being 13 years (22) and, in each of two series of patients, the oldest age of first awareness was 26 years $(20,22)$. Yet, in one of nine patients from three families, CLA was first noticed at age 52 years (19). Thirty of the 31 patients presented with CLA before the diagnosis of MEN 2A (22).

Scratching appears to play an important role in the pathogenesis of cutaneous amyloidosis by causing epidermal cell damage that leads to filamentous degeneration of keratinocytes, subsequent apoptosis, and conversion of filamentous masses into amyloid material (23). The neural crest cells, implicated in embryological development of the adrenal medulla and parafollicular C cells, are also involved in the embryogenesis of the thoracic sensory fibers and their impulses (25), a pattern that may explain the itch and subsequent scratch cycle predating other stigmata of the disorder. Whereas amyloid has been an almost invariable component in

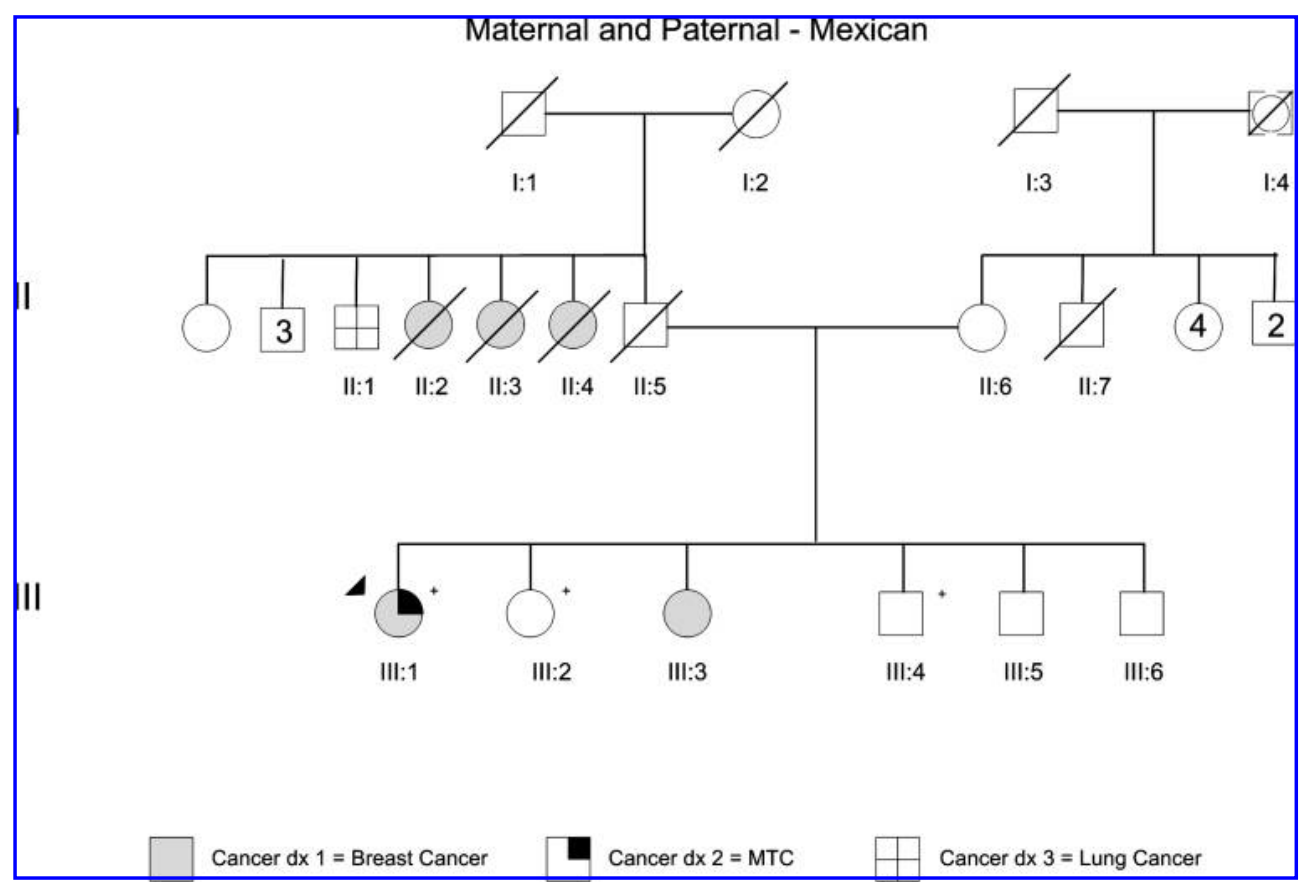

FIG. 4. Pedigree chart. Pedigree of the patient (arrowhead). The appearances of the RET mutation V804M (+) and of cancers (breast, medullary thyroid, and lung) are shown. The number of family members in generation II was large, and, for clarity in presentation, condensed: at the far left there were three males and one female, and at the far right there were four females and two males, each of whom was unaffected by cancer. Genetic analysis for V804M had been performed only in three members in generation III. 
the histologic picture of CLA, it may not be found in some biopsy specimens $(23,26)$.

FMTC is defined as MTC without other components of MEN 2A, and the usual chronology is a later in life onset and indolent progression. A number of RET mutations underlie FMTC and have appeared in exons 10,13,14, and $15(3,7)$ and 11 (3). Most patients with a V804M mutation have manifested the FMTC pattern, but a few, aged 54-55 years and exhibiting small MTC tumor(s), had features of MEN 2A; two presented with hyperparathyroidism $(17,18)$; two exhibited pheochromocytomas, unilateral adrenal tumor in one (15), and bilateral adrenal pheochromocytomas in the other (16). In patients with MEN 2A, hyperparathyroidism and pheochromocytomas generally appear chronologically after MTC (4). The commonly late onset of MTC in patients with the V804M mutation may obscure any predilections for hyperparathyroidism and pheochromocytomas. Our patient is the first with V804M to express the extra-thyroidal feature of CLA; thus, she does not conform to the strict criteria of FMTC. Other RET mutations that present as FMTC also appear as MEN 2A. Many families with C634Y have the multiple tumors of MEN 2A, while others present only FMTC (3). Although c804 has generally appeared as FMTC, members of one family with V804L mutation also exhibited pheochromocytomas (27).

In keeping with the usual pattern of FMTC, the MTC arising from V804M tends to appear in later years; in one series the mean age was 54 years (7). The carcinomas tended to be confined to the thyroid, but lymph node metastases have occurred $(7,8,10,12,13,15)$. Nevertheless, a patient with a mutation in c804 (precise mutation not stated) developed MTC at age 7 years (13), and one with the V804M mutation developed MTC at 6 years and died at age 12 years (12). As in our patient, basal calcitonin levels may be elevated at a time when there is only C-cell hyperplasia or little evidence of carcinoma $(8,12)$.

It is possible that CLA has been overlooked in many patients. Symptoms may be mild (19) and the lesion itself is not pathognomonic. Moreover, in patients with a V804M mutation as in our patient, the MTC may be clinically unapparent, and the genetic abnormality itself concealed. The genetic basis for CLA remains obscure; it does not appear to be related to the location of the codon; c634 is in the extracellular, cysteinerich domain, and c804 is in the intracellular, tyrosine-rich domain $(4,28)$.

In summary, we present a patient who exhibited a novel genotype-phenotype relationship: V804M and CLA. Her clinical appearance highlights that cutaneous disorders may be the earliest sign of malignancy. CLA in the interscapular area should prompt a search for MTC and MEN 2A. In addition, the patient is one of the few with the V804M mutation that is not expressed as FMTC.

\section{Acknowledgments}

We thank J. Ramirez, M.D., Department of Pathology, St. Joseph Mercy Hospital, Ypsilanti, Michigan, and D. Kim, M.D., Ph.D., Department of Dermatopathology, University of Michigan Medical Center, for providing the slides of the histopathology of the skin lesion, and T. Giordano, M.D., Department of Pathology, University of Michigan Medical Center, for providing slides of the thyroid carcinoma. We also thank William Herman, M.D., M.P.H., for his financial con- tribution toward the cost of publication. Carol Kruise provided expert help in creating the figures.

\section{Disclosure Statement}

The authors declare that no competing financial interests exist.

\section{References}

1. Nunziata V, Giannattasio R, Di Giovanni, D'Armiento MR, Mancini M 1989 Hereditary localized pruritis of a kindred with multiple endocrine neoplasia type 2A (Sipple's Syndrome). Clin Endocrinol 30:57-63.

2. Gagel R, Levy M, Donovan D, Alford B, Wheeler T, Tschen JA 1989 Mutliple endocrine neoplasia type 2A associated with cutaneous lichen amyloidosis. Ann Intern Med 111:802-806.

3. Eng C, Clayton D, Schuffnecker I, Eng C, Clayton D, Schuffenecker I, Lenoir G, Cote G, Gagel RF, van Amstel HK, Lips CJ, Nishisho I, Takai SI, Marsh DJ, Robinson BG, Frank-Raue K, Raue F, Xue F, Noll WW, Romei C, Pacini F, Fink M, Niederle B, Zedenius J, Nordenskjöld M, Komminoth P, Hendy GN, Mulligan LM, et al. 1996 The relationship between specific RET proto-oncogene mutations and disease phenotype in multiple endocrine neoplasia type 2. JAMA 276:1575-1579.

4. Yip L, Cote G, Shapiro S, Ayers G, Herzog C, Sellin R, Sherman S, Gagel R, Lee J, Evans D 2003 Multiple endocrine neoplasia type 2, evaluation of the genotype-phenotype relationship. Arch Surg 138:409-416.

5. Mulligan LM, Eng C, Healey C, Clayton D, Kwok J, Gardner E, Ponder M, Frilling A, Jackson C, Lehnert H, Neumann H, Thibodeau S, Ponder B 1994 Specific mutations of the RET proto-oncogene are related to disease phenotype in MEN 2A and FMTC. Nat Genet 6:70-74.

6. Lesueur F, Cebrian A, Cranston A, Leyland J, Faid RM, Clements MR, Robledo M, Whittaker J, Ponder BA 2005 Germline homozygous mutations at codon 804 in the RET protooncogene in medullary thyroid carcinoma/multiple endocrine neoplasia type 2A patients. J Clin Endocrinol Metab 90:3454-3457.

7. Niccoli-Sire P, Murat A, Rohmer V, Franc S, Chabrier G, Bldet L, Maes B, Savagner F, Giraud S, Bezieau S, Kottler M-L, Morange S, Conte-Devolx B, The French Calcitonin Tumors Study Group (GETC) 2001 Familial medullary thyroid carcionma with noncysteine RET mutations: phenotypegenotype relationship in a large series of patients. J Clin Endocrinol Metab 86:3746-3753.

8. Feldman G, Edmonds M, Ainsworth P, Schuffenecker I, Lenoir G, Saxe A, Talpos G, Roberson J, Petrucelli N, Jackson C 2000 Variable expressivity of familial medullary thyroid carcinoma (FMTC) due to a RET V804M (GTG $\rightarrow$ ATG) mutation. Surgery 128:93-98.

9. Baumgartner-Parzer SM, Lang R, Wagner L, Heinze G, Niederle B, Kaserer K, Waldhäusl W, Vierhapper H 2005 Polymorphisms in exon 13 and intron 14 of the RET protooncogene: genetic modifiers of medullary thyroid carcinoma? J Clin Endocrinol Metab 90:6232-6236.

10. Jindrichová $S$, Vcelák J, Vlcek $P$, Neradilová $M, N e m e c ~ J$, Bendlová B 2004 Screening of six risk exons of the RET proto-oncogene in families with medullary thyroid carcinoma in the Czech Republic. J Endocrinol 183:257-265.

11. Lecube A, Hernandez C, Oriola J, Galard R, Gémar E, Mesa J, Simó R 2002 V804M RET mutation and familial medullary thyroid carcinoma: report of a large family with expression 
of the disease only in the homozygous gene carriers. Surgery 131:509-514.

12. Frohnauer M, Decker R 2000 Update on the MEN 2A c804 RET mutation. Is prophylactic thyroidectomy indicated? Surgery 128:1052-1058.

13. Gimm O, Ukkat J, Niederle BE, Weber T, Thanh P, Brauckhoff M, Niederle B, Dralle H 2004 Timing and extent of surgery in patients with familial medullary thyroid carcinoma/mutliple endocrine neoplasia 2A-related RET mutations not affecting codon 634. World J Surg 28:1312-1316.

14. Magalhäes P, de Castro M, Elias L, Soares E, Maciel L 2004 Polymorphisms in the RET proto-oncogene and the phenotypic presentation of familial medullary thyroid carcinoma. Thyroid 14:848-852.

15. Scacheri P, Crabree J, Kenndy A, Swain G, Ward J, Marx S, Spiegel A, Collins F 2006 V804 RET mutation in MEN2A: first report. J Int Med 255:712 (abstract).

16. Recasens M, Oriola J, Fernandez-Real JM, Roig J, RodriquezHermosa JI, Font JA, Galofre P, Lopez-Bermejo A, Ricart W 2007 Asymptomatic bilateral adrenal pheochromocytomas in a patient with a germ-line V804M mutation in the RET proto-oncogene. Clin Endocrinol 67:29-33.

17. Gibelin H, Bezieau S, Misso C, Bouin-Pineau M-H, Maréchaud R, Kraimps J-L 2004 Germline RET V804M mutation associated with multiple endocrine neoplasia type $2 \mathrm{~A}$. Br J Surg 91:1458-1459.

18. Pinna G, Orgiana G, Riola A, Ghiani M, Lai M, Carcassi C, Mariotti S 2007 RET proto-oncogene in Sardinia: V804M is the most frequent mutation and may be associated with FMTC/MEN-2A phenotype. Thyroid 17:101-104.

19. Verga U, Fugazzola L, Cambiaghi S, Pritelli C, Alessi E, Cortelazzi D, Gangi E, Beck-Peccoz P 2003 Frequent association between MEN 2A and cutaneous lichen amyloidosis. Clin Endocrinology 59:156-161.

20. Ferrer J, Halperin I, Conget J, Alsina M, Martinez-Osaba M, Palou J, Bombi J, Vilardell E 1991 Primary localized cutaneous amyloidosis and familial thyroid carcinoma. Clin Endocrinol 34:435-439.

21. Abdullah F, Udelsman R 2004 Cutaneous lichen amloidosis in a family with familial medullary thyroid cancer. Surgery 135:563-564.

22. Robinson $M$, Furst $E$, Nunziata $V$, Brandi $M$, Ferrer J, Martins Bugalho M, di Giovanni G, Smith R, Donovan D, Alford B,
Hejtmancik J, Colantuoni V, Quadro L, Limbert E, Halpeprin I, Vilardell E, Gagel R 1992 Characterization of the clinical features of five families with hereditary primary cutaneous lichen amyloidosis and multiple endocrine neoplasia type 2 . Henry Ford Hosp Med J 40:249-252.

23. Chabre O, Labat F, Pinel N, Berthod F, Tarel V, Bachelot I 1992 Cutaneous lesion associated with multiple endocrine neoplasia type 2A: lichen amyloidosis or notalgia paresthetica? Henry Ford Hosp Med J 40:245-248.

24. Hofstra RM, Sijmons RH, Stelwagen T, Stulp RP, Kousseff BG, Lips CJ, Steijlen PM, Van Voorst Vader PC, Buys CH 1996 RET mutation screening in familial cutaneous lichen amyloidosis and in skin amyloidosis associated with multiple endocrine neoplasia. I Invest Dermatol 107:215218.

25. Kousseff B, Espinoza C, Zaomore G 1991 Sipple syndrome with lichen amyloidosis as a paracrinopathy: pleiotropy, heterogeneity, or a contiguous gene? I Am Acad Dermatol 25:651-657.

26. Nunziata V, di Giovanni G, Lettera AM, D'Armiento M, Mancini M 1989 Cutaneous lichen amyloidosis associated with multiple endocrine neoplasia type 2A. Henry Ford Hosp Med J 37:144-146.

27. Nillson O, Tisell L, Jansson S, Ahlman H, Gimm O, Eng C 1999 Adrenal and extra-adrenal pheochromocytomas in a family with germline RET V804L mutation, letter to the editor. JAMA 281:1587-1588.

28. Machens A, Niccoli-Sire $P$, Hoegel J, Frank-Raue $K$, van Vroonhoven T, Roeher H, Wahl R, Lamesch P, Raue F, Conte-Devolx B, Dralle H for the European Mutliple Endocrine Neoplasia (EUROMEN) Study Group 2003 Early malignant progression of hereditary medullary thyroid cancer. N Engl J Med 349:1517-1525.

Address reprint requests to: Amy E. Rothberg, M.D.

Division of Metabolism, Endocrinology, and Diabetes Department of Internal Medicine University of Michigan

1500 E. Medical Center Drive, TC 3920 Ann Arbor, MI 48109-5354

E-mail: arothber@med.umich.edu 

This article has been cited by:

1. S Mukherjee, D Zakalik. 2010. RET codon 804 mutations in multiple endocrine neoplasia 2: genotype-phenotype correlations and implications in clinical management. Clinical Genetics no-no. [CrossRef] 